\title{
Energy Absorption and Deformation Pattern Analysis of Initial Folded Crash Box Subjected to Frontal Test
}

\author{
Moch. Agus Choiron a, Zumrotul Ida ${ }^{b}$, Anindito Purnowidodo ${ }^{c}$, Ahmad Rivai ${ }^{d}$ \\ a, b, c Department of Mechanical Engineering, Brawijaya University \\ ${ }^{d}$ Faculty of Mechanical Engineering, Universiti Teknikal Malaysia Melaka \\ e-mail: agus choiron@ub.ac.id
}

\begin{abstract}
Crash box design as one of the passive safety components in a vehicle had been developed to enhance energy absorption. Initial fold on the crash box is set to facilitate folding during the crash. The aims of this study is to investigate the initial folded crash box with length to thickness ratio subjected to frontal test. The frontal test is modelled by using finite element analysis. Through computer simulation using 9 models, the obtained result was used to provide the better design of crash box. The variations in this study were length to thickness ratio of crash box with length of tube $(L)=115$; 132.5; $150 \mathrm{~mm}$ and the thickness of tube $(t)=1.6 ; 2.0 ; 2.5 \mathrm{~mm}$. The crash box material was assumed as bilinear isotropic hardening material. The velocity used in the simulations was $7.67 \mathrm{~m} / \mathrm{s}$ with impact mass of $103 \mathrm{~kg}$. Based on the results, it can be shown that $1^{\text {st }}$ model to $8^{\text {th }}$ model produce deformation pattern as concertina mode and $9^{\text {th }}$ model has diamond mode. The $3^{\text {rd }}$ model has the largest energy absorption with value of $18.29 \mathrm{~kJ}$.
\end{abstract}

Keywords: Initial folded crash box; energy absorption; deformation pattern; frontal test

\section{INTRODUCTION}

The development of modern society is increasing human demand for transportation. Based on the end of 2016 data, the number of car sales in Indonesia reached 1,062,729 units [1]. Unfortunately, as increasing the number of vehicles, the number of traffic accident has also increased significantly. Only two months (January - March 2017), traffic accident reported is 24,268 cases and the car was the second causes of this accident after motorcycle [2].

The crash box is one of the passive safety components in vehicle located at the front and rear between bumper and frame. It's function as energy absorber due to collisions result in plastic deformation. In the crash box mechanism, the kinetic energy is dissipated by progressive deformation at collision and the minimum amount of force is transferred to the occupants. The study of deformation modes and energy absorption performance had been done for various section geometries of crash box and compared both experimentally and numerically [3]. In the next study, many researches carried out on initial folding sections technique to produce more folding by adding grooves, corrugations and patterns [4][5]. Initial folded produce more folding and exhibits good impact resistance. In other technique, the crash box with holes is designed to create as pre-folding corresponding to the peak of crush force reducing [6]. In the multi-segments crash box, variation on segment combinations of crash box was intended to obtain the better performance in 
crash energy absorbing [7]. The four-segmented aluminum tubes with circular cross sections were investigated with the length, thickness and mechanical properties of each tube segment varies along the length [8]. Based on these reasons, effects of changing the wall thickness and length of each segment are important parameter design. In this study, initial fold crash box is investigated to evaluate the deformation pattern and energy absorption with various length to thickness ratio.

\section{Methodology}

The computer simulation was done by the ANSYS 14.5 academic software based on Finite Element Analysis. Figure 1 shows the geometry of crash box design. The details of variations of Length $(\mathrm{L})$ to Thickness ( $\mathrm{t}$ ) ratio can be seen in Table 1. The angle of initial fold crash box is set as $90^{\circ}$ with 1:1 of fold ratio. The crash box material is Mild Steel ASTM E-04 based on the previous study [9] and the material is assumed as Bilinear Isotropic Hardening as shown in the Table 2.1.

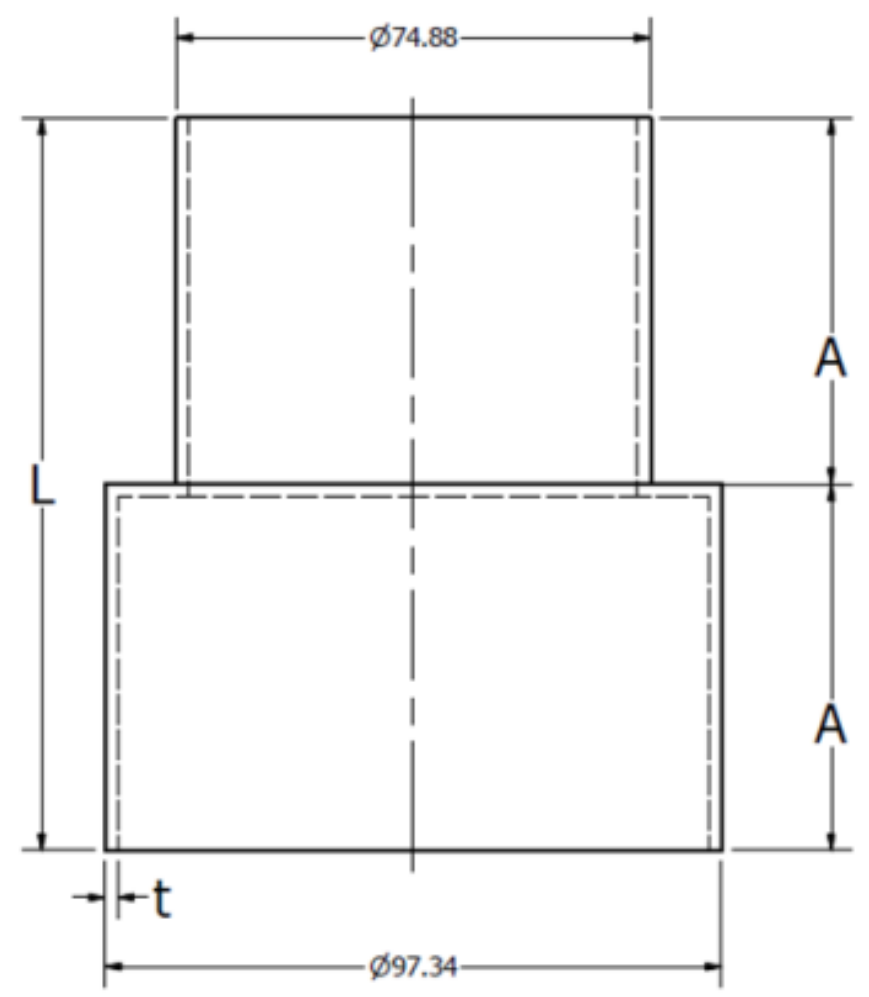

Figure 2.1 Geometry of crash box design

Table 2.1 Initial fold crash box model with various length to thickness ratio

\begin{tabular}{lcccc}
\hline No. & $\begin{array}{c}\text { Crash } \\
\text { box }\end{array}$ & $\mathbf{L}(\mathbf{m m})$ & $\mathbf{t}(\mathbf{m m})$ & $\begin{array}{c}\text { Ratio } \\
\text { L/t }\end{array}$ \\
\hline 1 & Model 1 & 115 & 1.6 & 71.8 \\
2 & Model 2 & 115 & 2.0 & 57.5 \\
3 & Model 3 & 115 & 2.5 & 46 \\
4 & Model 4 & 132.5 & 1.6 & 82.8 \\
5 & Model 5 & 132.5 & 2.0 & 66.2 \\
6 & Model 6 & 132.5 & 2.5 & 53 \\
7 & Model 7 & 150 & 1.6 & 93.7 \\
8 & Model 8 & 150 & 2.0 & 75 \\
9 & Model 9 & 150 & 2.5 & 60 \\
\hline
\end{tabular}


The diameter of circular tube was set as constant of $97.34 \mathrm{~mm}$. Shell element has been used to mesh crash box model with element size of $1.3 \mathrm{~mm}$. The velocity of impactor used in the simulations was $7.67 \mathrm{~m} / \mathrm{s}$ with impact mass $103 \mathrm{~kg}$. Impactor was modeled as a rigid body. Contact between the crash box, impactor and fixed support were set as bounded contact. The boundary conditions of model can be seen in Figure 2 . In term of the crash box performance indicators, deformation pattern and energy absorption are observed.

Table 2.2 Material properties of crash box

\begin{tabular}{ll}
\hline Density $\left(\mathrm{kg} / \mathrm{m}^{3}\right)$ & $8,077 \times 10^{3}$ \\
Modulus Young (MPa) & $2,05 \times 10^{5}$ \\
Poisson's Ratio & $2,9 \times 10^{-1}$ \\
Yield Strength (MPa) & $2,6694 \times 10^{2}$ \\
Tangent Modulus (MPa) & $2,6667 \times 10^{3}$ \\
\hline
\end{tabular}

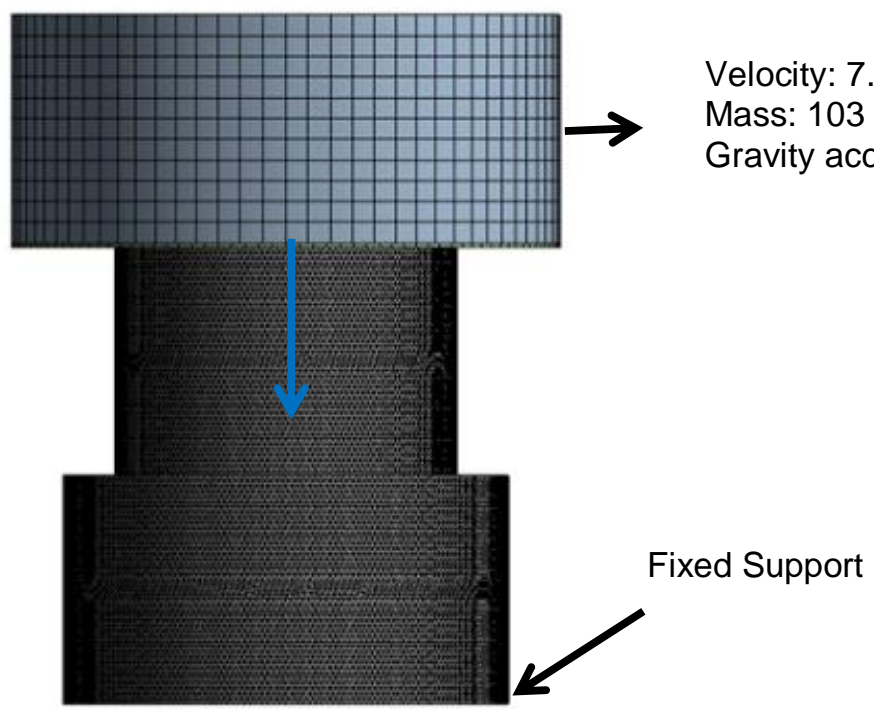

Figure 2.2 Meshing and boundary conditions of model

\section{Result AND Discussion}

From the computer simulation results, it can be obtained the energy absorption results on all models as shown in the Table 3.1. Based on the table, it can be shown that the $3^{\text {rd }}$ model with length of $115 \mathrm{~mm}$ and thickness of $2.5 \mathrm{~mm}$ has the largest energy absorption.

\begin{tabular}{|c|c|}
\hline Crash box & Energy Absorption ( $\mathrm{J}$ ) \\
\hline Model 1 & 8376.54 \\
\hline Model 2 & 12222.63 \\
\hline Model 3 & 18294.06 \\
\hline Model 4 & 6775.44 \\
\hline Model 5 & 8602.44 \\
\hline Model 6 & 13518.13 \\
\hline Model 7 & 5991.03 \\
\hline Model 8 & 8405.36 \\
\hline Model 9 & 11904.93 \\
\hline
\end{tabular}


In the frontal test on crash box, deformation pattern can occur as concertina (axisymmetric), diamond or mixed mode [10]. The deformation pattern occurred in each models can be seen in Table 3.2. Visual analysis on these result shows each models has similar deformation pattern in the initial loading. First folding occurred in the inside of initial fold. After the wall crash the fixed support, folding of upper and bottom of crash box is occurred (Figure 3.1). Based on the table, it can be shown that $1^{\text {st }}-8^{\text {th }}$ models produce deformation pattern as concertina mode, and $9^{\text {th }}$ model has diamond mode.

Table 3.2 Deformation Pattern on Models

\begin{tabular}{ccccc}
\hline No & Deformation $(\mathrm{mm})$ & Top View & $\begin{array}{c}\text { Deformation } \\
\text { Mode }\end{array}$ \\
\cline { 2 - 3 } & $\mathbf{2 9 . 3 1}$ & $\mathbf{7 8 . 1 7}$ & 91.71 &
\end{tabular}

1
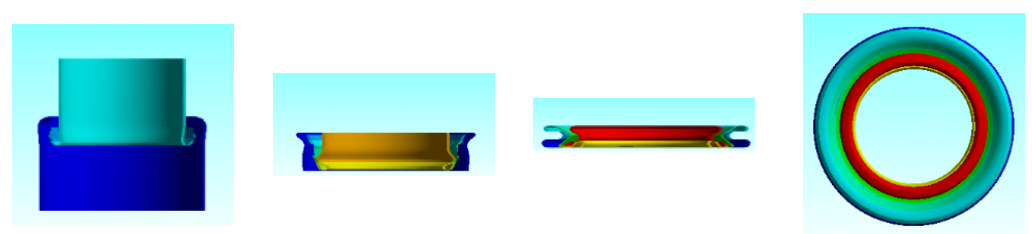

Concertina

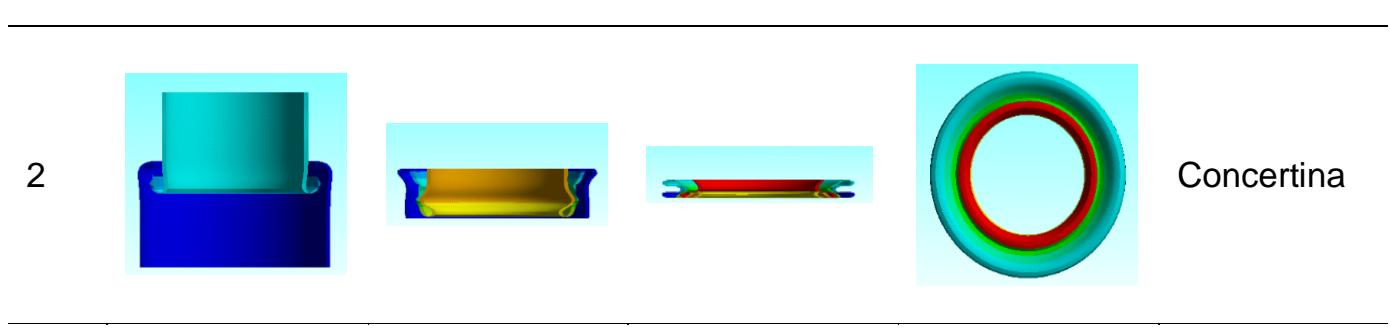

3
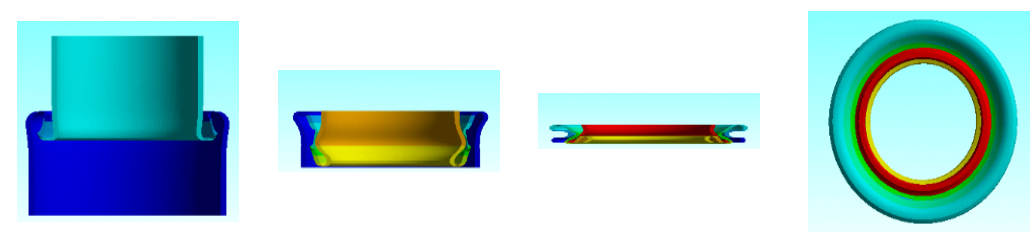

Concertina

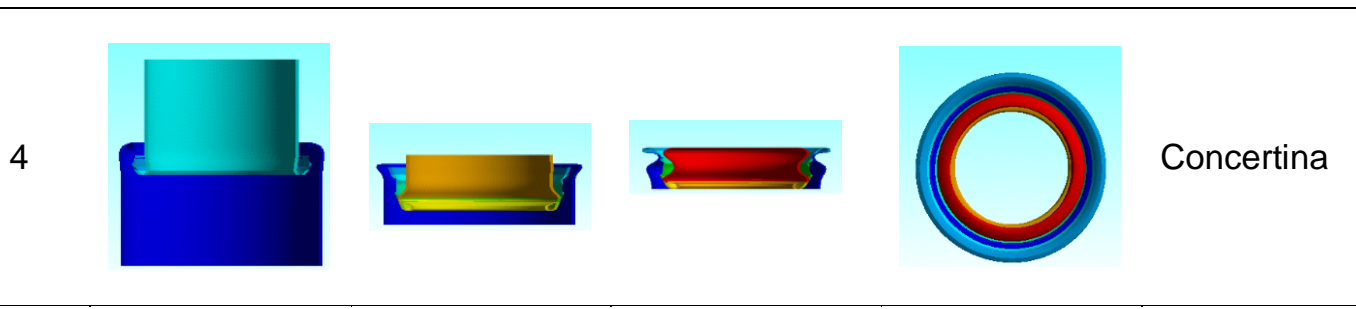

5
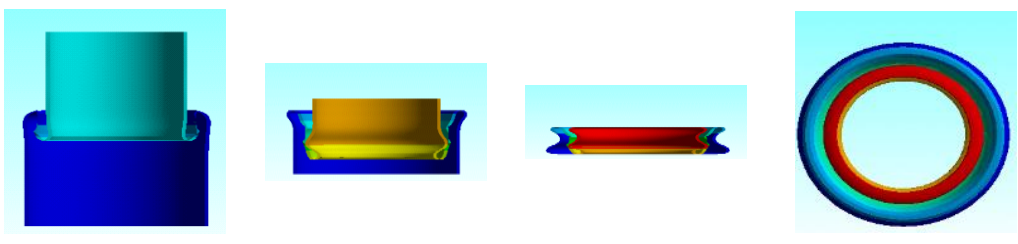

Concertina

6
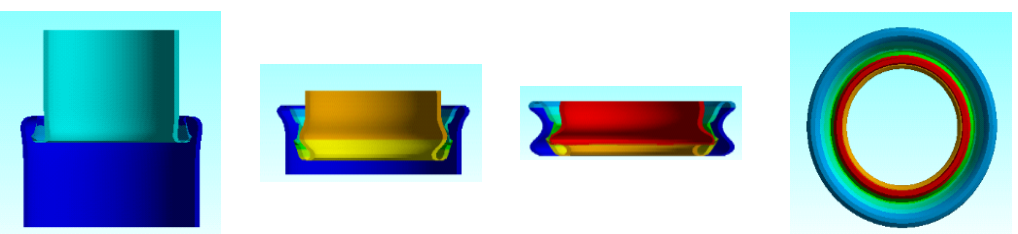

Concertina

JEMMME | Journal of Energy, Mechanical, Material, and Manufacturing Engineering 

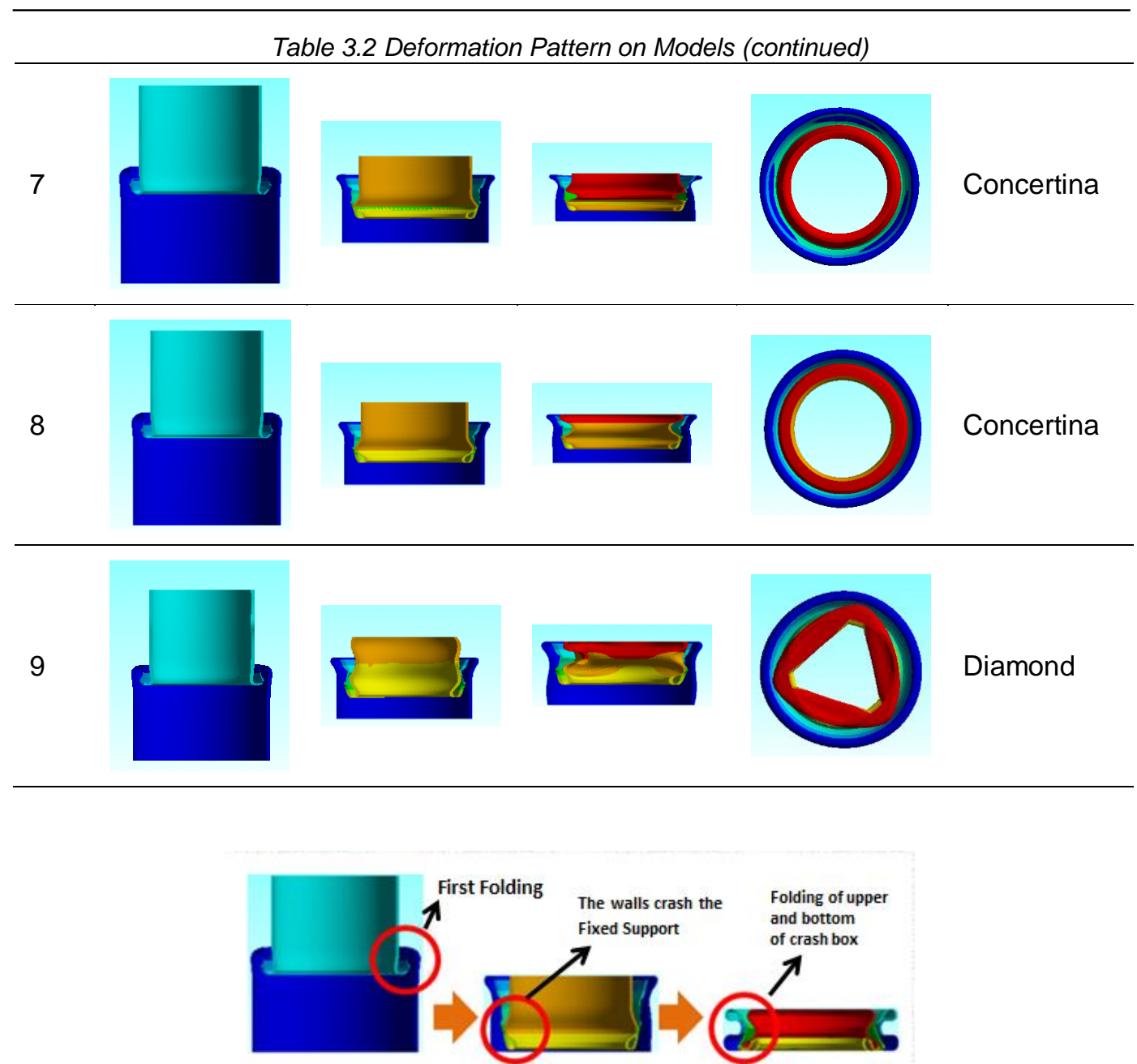

Figure 3.1 Folding Process of $3^{\text {rd }}$ Model

Figure 3.2 shows the deformation pattern connected with energy absorption on $3^{\text {rd }}$ Model. At the beginning deformation, the energy absorption curve tends in the straight line, and the first folding is occurred caused by the first peak of loading connected with increasing of energy absorption. In the next folding, energy absorption curve perform increase as the fact that this design exhibits good impact resistance due to collisions result in plastic deformation with number of folding occurred $[3,10]$.

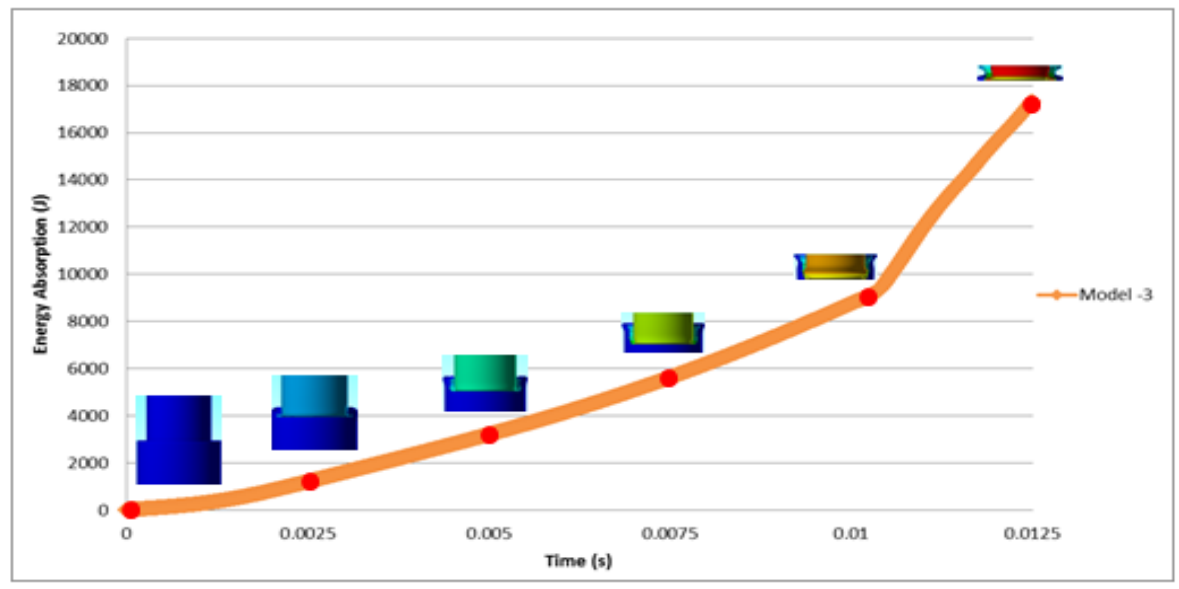

Figure 3.2 Deformation Pattern and Energy Absorption on $3^{\text {rd }}$ Model

JEMMME | Journal of Energy, Mechanical, Material, and Manufacturing Engineering 


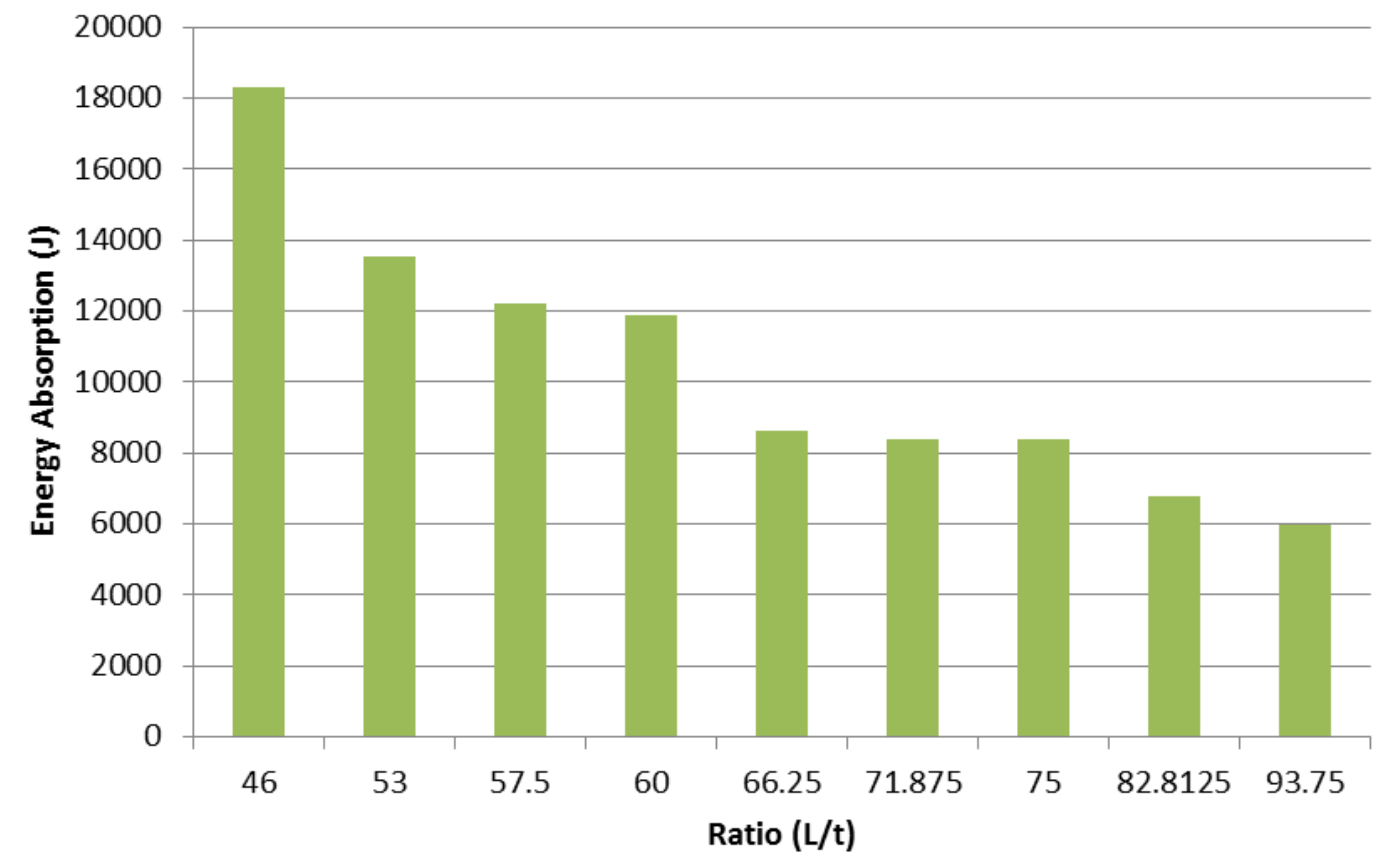

Figure 3.3 Energy absorption on length-thickness ratio variation

As shown in the Figure 3.3, high value of energy absorption is obtained by decreasing the length to thickness ratio of crash box. In other analysis, specific energy absorption is defined as the energy absorbed per unit of mass. This magnitude is considered due to increasing of length to thickness ratio connected with increasing of crash box mass. The mass and the specific energy absorption can be seen in Figure 3.4 and Table 3.3.

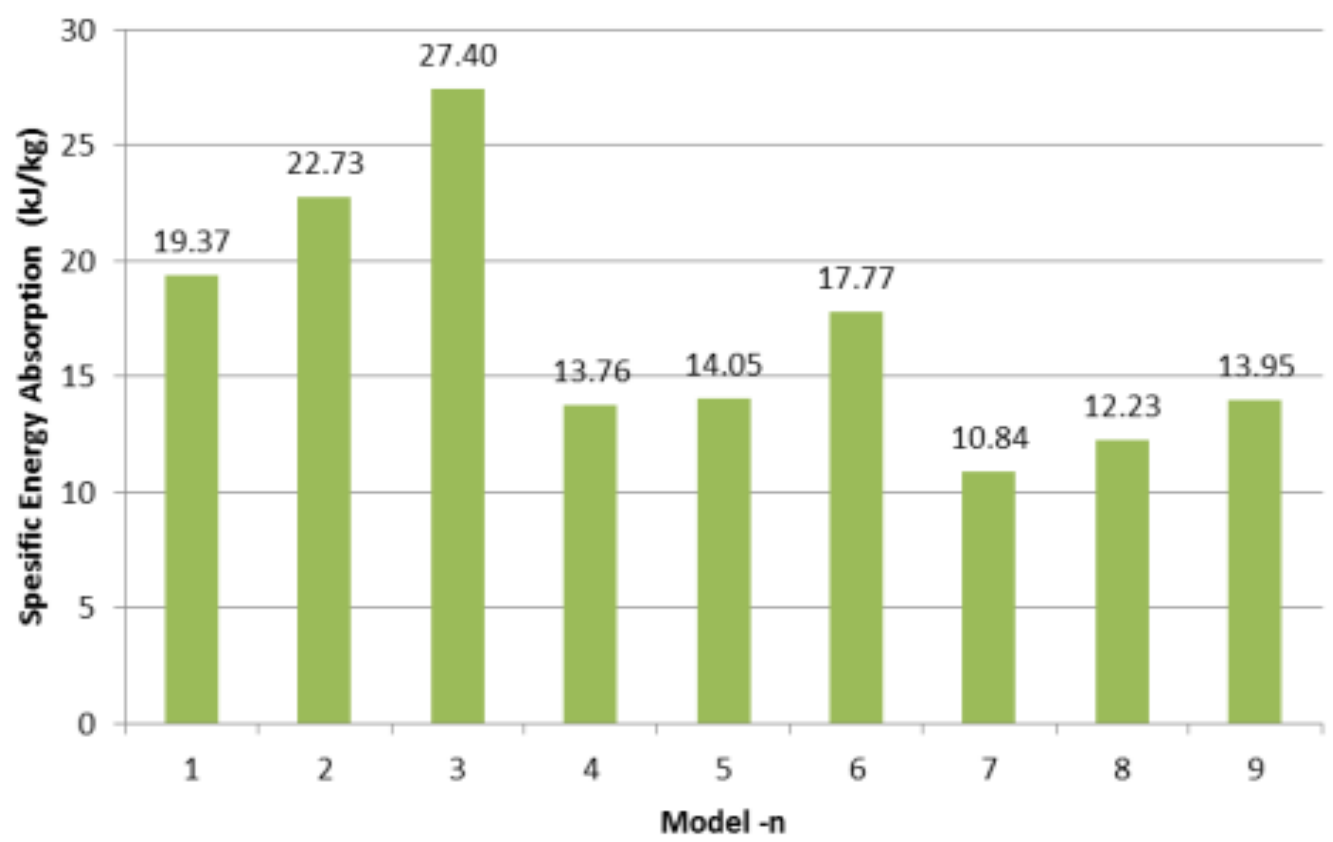

Figure 6. Specific energy absorption on all models 
Crash box length of $115 \mathrm{~mm}$ and thickness of $2.5 \mathrm{~mm}$ produce largest specific energy of absorption with $27.39 \mathrm{~kJ} / \mathrm{kg}$. It can be concluded that increasing of thickness will increasing the value of specific energy absorption. Meanwhile, as increasing the number of length, the value of specific energy absorption has decreasing. High value of specific energy absorption is determined by decreasing the ratio length and thickness of crash box.

Table 3.3 Mass and specific energy absorption of models

\begin{tabular}{cccc}
\hline $\begin{array}{c}\text { Crash } \\
\text { box }\end{array}$ & $\begin{array}{c}\text { Mass } \\
\mathbf{( k g )}\end{array}$ & $\begin{array}{c}\text { Energy } \\
\mathbf{( k J )}\end{array}$ & $\begin{array}{c}\text { Specific Energy } \\
\mathbf{( k J / k g )}\end{array}$ \\
\hline 1 & 0.43237 & 8.37 & 19.37 \\
2 & 0.53768 & 12.22 & 22.73 \\
3 & 0.66773 & 18.29 & 27.39 \\
4 & 0.49242 & 6.77 & 13.75 \\
5 & 0.61237 & 8.60 & 14.04 \\
6 & 0.76055 & 13.52 & 17.77 \\
7 & 0.55246 & 5.99 & 10.84 \\
8 & 0.68707 & 8.40 & 12.23 \\
9 & 0.85337 & 11.90 & 13.95 \\
\hline
\end{tabular}

\section{Conclusion}

Crash simulation under frontal load was carried out on initial fold crash box design to obtain better performance in crash energy absorbing. From the results of this study, it can be concluded that $1^{\text {st }}-8^{\text {th }}$ models produce deformation pattern as concertina mode, and $9^{\text {th }}$ model has diamond mode. The $3^{\text {rd }}$ model has the largest energy absorption with value $18,29 \mathrm{~kJ}$.

\section{REFERENCES}

[1] The Association of Indonesia Automotive Industries (2016). Domestic Auto Market \& Exim by Category 2016. Indonesia, GAIKINDO.

[2] Traffic Accident Statistic on Indonesia 2017, KORLANTAS POLRI.

[3] Ali Alavi Nia, Jamal Haddad Hamedani (2010). Comparative Analysis of Energy Absorption and Deformations of Thin Walled Tubes with Various Section Geometries, Thin-Walled Structures 48, 946-954.

[4] Daneshi GH, Hosseinipour SJ (2002). Grooves Effect on Crashworthiness Characteristics of Thin-Walled Tubes Under Axial Compression. Mater Design 23(7), 611-7.

[5] Xiong Zhang, Gengdong Cheng, Zhong You, Hui Zhang (2007). Energy absorption of Axially Compressed Thin-Walled Square Tubes with Patterns, Thin-Walled Structures 45, $737-746$.

[6] Choiron M. A., Sudjito, and Hidayati, N.A. (2016). Crash energy absorption of twosegment crash box with holes under frontal load, AIP Conference Proceedings 1717 , 050009; doi: 10.1063/1.4943484.

[7] Choiron M. A., Purnowidodo A., Siswanto E., and Hidayati, N.A. (2016). Crash Energy Absorption of Multi-Segments Crash Box Under Frontal Load. Jurnal Teknologi (Sciences \& Engineering) 78:5, 347-350. 
[8] V. Jandaghi Shahi, J. Marzbanrad (2012). Analytical and Experimental Studies On Quasi-Static Axial Crush Behavior of Thin-Walled Tailor-Made Aluminum Tubes, Thin-Walled Structures 60, 24-37.

[9] Velmurugan, R., Muralikannan, R. (2009). Energy Absorption Characteristic of Annealed Steel Tubes of Various Cross Sections in Static and Dynamic Loading. Latin American Journal of Solid Structures 6, 385-412.

[10]Bardi, F. C. dan Kyriakides, S. (2006). Plastic buckling of Circular Tubes Under Axial Compression-Part I: Experiments. International Journal of Mechanical Sciences. 48(8), 830-841. 